\title{
Management of Citrus Tree Canopies for Fresh-Fruit Production ${ }^{1}$
}

\author{
Andrew Krajewski, Arnold Schumann, Tim Ebert, Chris Oswalt, Rhuanito S. Ferrarezi, and \\ Laura Waldo ${ }^{2}$
}

Canopy management for citrus has two components: selective pruning, and management of the resulting vegetative regrowth. Selective pruning means pruning trees at the correct time in their phenological cycle. Correct cutting techniques are used to remove only specific, unwanted branches. Regrowth management usually consists of thinning out excess vegetative shoots resulting from pruning. Where appropriate, it may also involve the bending of upright, very vigorous, but otherwise well-placed watershoots to hasten their transition to bearing. Canopy management is a useful tool to induce precocity and maintain high production of optimum-sized, high-quality fruit. It also helps other management practices (e.g., interrow access; fertigation and servicing of irrigation systems; scouting; pest and disease sprays; weed management; and grove sanitation and harvest). Correct canopy management of both nonbearing and bearing trees is especially important in higher-density planting systems such as CUPS (Citrus Under Protective Screen; Schumann et al. 2017), where crowding and shading are issues requiring management if trees are to produce sustained and consistent high yields of uniformly excellent fruit. The aim of this article is to provide growers with practical tools with which to manage their trees for maximum fresh-fruit yield, quality, and profitability.
Canopy management has three goals to attain or maintain optimal production. A tree is a factory with sunlight, water, and fertilizer as inputs and fruit as the output. For best production the tree needs these materials in the right quantity at the right time. In times of plenty and low need, it stores materials in roots, stems, and leaves. As in any factory, greater efficiency is attained with shorter supply chains. Fruit at the end of long spindly branches may have ample light but are farther from water and minerals. The first goal of pruning is to help the tree produce fruit closer to the raw materials used to mature the fruit. Pruning is to improve light penetration (goal 1) and maintain a simple pattern of main branches to keep supply chains short (goal 2). Trees may overproduce where there are too many flowers resulting in too many fruit. The outcome is a bumper crop of small fruit that stresses the tree and results in alternate bearing cycles. Pruning is one approach to fruit thinning (goal 3). Maintaining these three goals will have several beneficial side effects, such as better spray penetration and easier harvesting at the end of the production cycle. We will return to these concepts in different ways to add critical details in achieving these goals.

1. This document is SL485, one of a series of the Department of Soil and Water Sciences, UF/IFAS Extension. Original publication date January 2021. Visit the EDIS website at https://edis.ifas.ufl.edu for the currently supported version of this publication.

2. Andrew Krajewski, PhD, International Citrus Technologies Pty. Ltd., Emu Point, Western Australia; Arnold Schumann, professor, Department of Soil and Water Sciences; Tim Ebert, postdoctoral associate, UF/IFAS Citrus Research and Education Center; Chris Oswalt, multicounty citrus Extension agent, UF/ IFAS Extension Polk County; Rhuanito S. Ferrarezi, assistant professor, UF/IFAS Indian River Research and Education Center; and Laura Waldo, biological scientist III, UF/IFAS Citrus REC; UF/IFAS Extension, Gainesville, FL 32611.

The Institute of Food and Agricultural Sciences (IFAS) is an Equal Opportunity Institution authorized to provide research, educational information and other services only to individuals and institutions that function with non-discrimination with respect to race, creed, color, religion, age, disability, sex, sexual orientation, marital status, national origin, political opinions or affiliations. For more information on obtaining other UF/IFAS Extension publications, contact your county's UF/IFAS Extension office. U.S. Department of Agriculture, UF/IFAS Extension Service, University of Florida, IFAS, Florida A \& M University Cooperative Extension Program, and Boards of County Commissioners Cooperating. Nick T. Place, dean for UF/IFAS Extension. 


\section{Canopy Management of Nonbearing Trees}

Correct pruning is a reliable, useful, and practical tool widely used to shape young trees for a strong, balanced canopy that can intercept more light, sustain high production, and ease future management. Young trees are trained toward a mechanically strong, geometrically balanced form in the first year after planting. This allows the efficient partitioning of stored reserves, energy, and growth to wellpositioned branches. If done early in the grove's life, such pruning lays the foundation for keeping trees within their allocated space and sustained high production. Do not wait for young trees to fill their allocated space before starting a pruning program. By then, considerable energy and tree reserves will have been wasted on poorly positioned branches that require removal anyway. In larger trees, pruners will also have to contend with thick, well-established branches that are harder to remove, set the trees back, and result in excessive production of overly vigorous regrowth. The resulting vegetative regrowth will itself require further management if the adverse effects of shading and excess canopy density are to be avoided. The amount of canopy management required also depends on the initial form of the tree supplied by the nursery. Some trees require little if any manipulation; others require significant work to get their basic structure right. Young trees may be trained as soon as they have established themselves. Trees are usually revisited in both spring and summer to early fall in their first year, with the aim of training them into forms that efficiently occupy their allocated space, are amenable to other cultural practices, and are mechanically capable of bearing the fruit load. The following steps are recommended:

- To maximize tree growth, strip all fruit from young trees in their first year of production.

- Use sterilized cutting instruments. This is discussed under the section "General Considerations."

Decide on the standard height above soil level of the lowest limb that will be allowed to develop on the trees. This is usually 45 to $65 \mathrm{~cm}$ (ca. 18 to 26 inches) above soil level. Keep the rootstock, bud union, and trunk clear of all growth below this point by carefully rubbing off new shoots by hand or using pruning shears (secateurs) to cut older branches (Figure 1). Failure to do so usually results in dominant, out-of-place branches (Figure 2) that shade more favorably placed branches and compete with them for sap flow and nutrients, or branches so low that they or their fruit touch the soil surface.

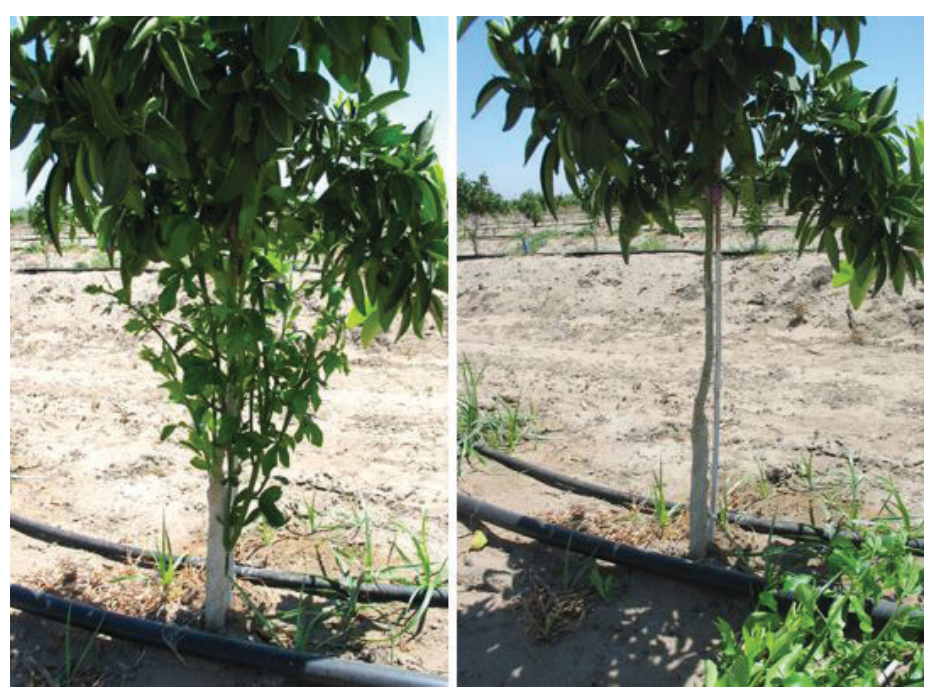

Figure 1. Removal of sucker shoots from rootstock, bud union, and tree trunk, before (left) and after (right). These suckers compete with the tree canopy above for water and nutrients. Remove these as soon as they arise in both nonbearing and bearing trees through the life of the grove.

Credits: International Citrus Technologies Pty Ltd, Western Australia

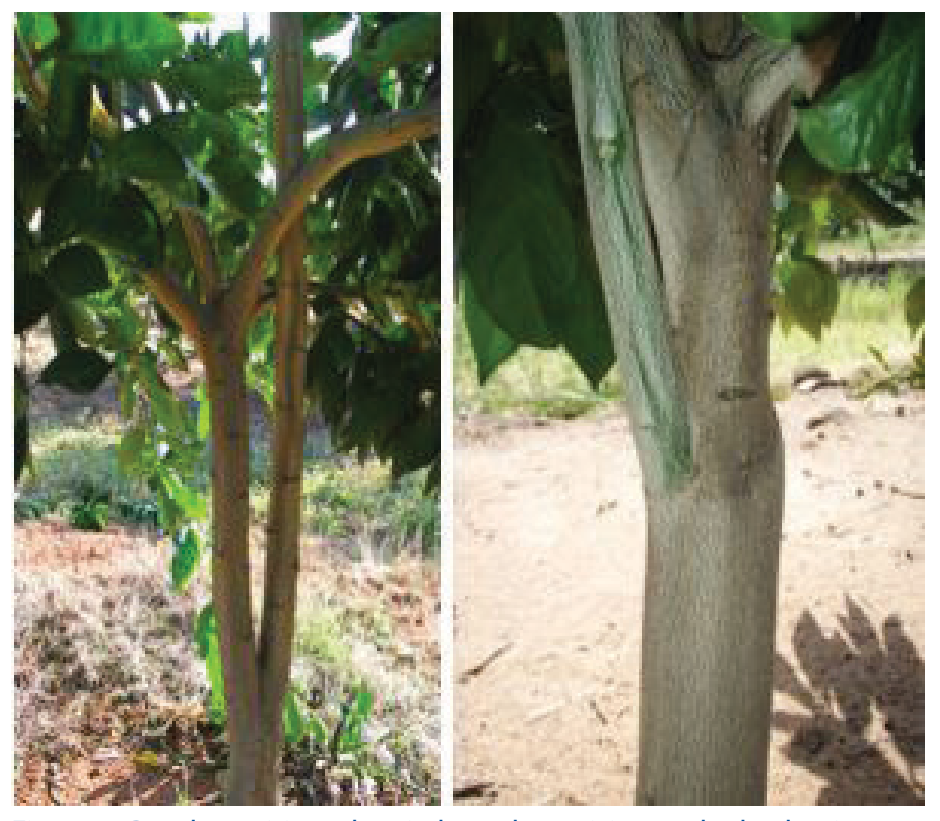

Figure 2. Poorly positioned main branches arising at the bud union and below the level of the tree's main branches allowed to develop on a low-budded tree (left) and high-budded tree (right). Both cases result in mechanically weak branches that are prone to breakage when laden or during storms. They also shade, dominate, and compete with well-placed branches in the canopy and should already have been removed long before they reached this size.

Credits: International Citrus Technologies Pty Ltd, Western Australia

- Remove dead or diseased branches at once. Also remove any broken branches. This can sometimes be a drastic operation where trees were left to form their own branch structure and in cultivars with inherently brittle wood (Figure 3). It may be easier and more effective to remove branches heavily infested with scale insects. Heavy 
infestations can weaken branches, and already stressed branches may be more susceptible to heavy infestations.

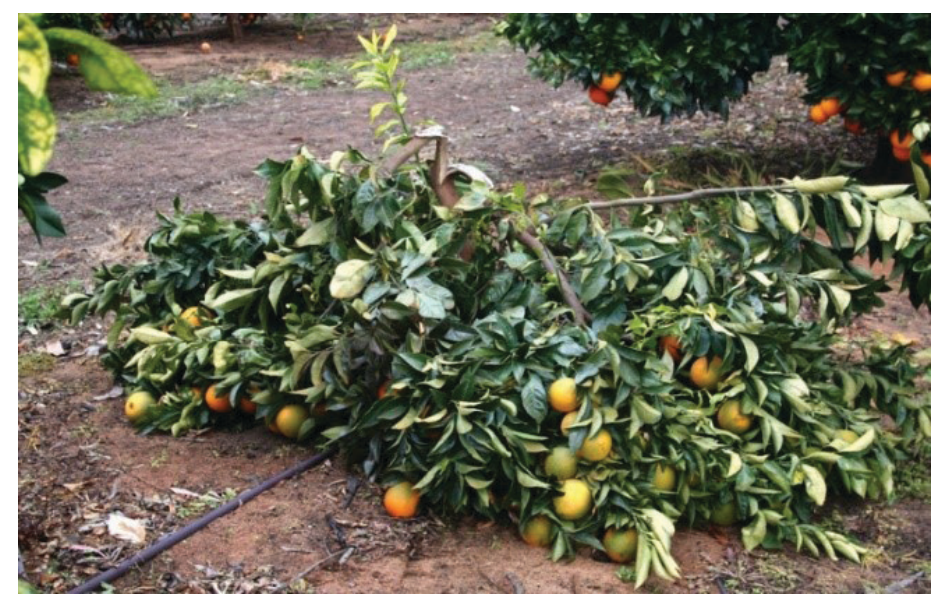

Figure 3. Branch breakage under fruit load: the result of leaving young trees untrained, leading to poor scaffold branch placement and mechanically weak trees.

Credits: International Citrus Technologies Pty Ltd, Western Australia

- Select those major branches best placed to form the main scaffolds or structural limbs. These branches, usually 3 to 6 per tree, should be correctly spaced; orientated to radiate outwards from the tree's center like the spokes of a wheel; and of equal dominance and vigor (see example Figure 4). Remove unwanted branches, such as "crossovers" growing back toward the tree centers instead of radiating outward; those growing sideways over the top of another branch; and any branch that lies in direct contact across another better-positioned one (discussed and illustrated later). Finally, thin out forked branches that lie alongside each other and occupy the same space in the canopy. Leave the best-positioned, best-shaped branch in place and remove the others. Where branches fork one above the other ("over-under" forks), always remove the lower fork. When removing these kinds of unwanted branches, cut flush with the points of attachment through the so-called branch "collar" using sharp, sterilized instruments. Try to avoid damaging the bark. Nonbearing trees should be skirted at a height that prevents physical contact of low branches with the ground or with soil splash. This may be achieved by shortening the branch in question back to a convenient side-branch to redirect the growth. A skirting height of 45 to $65 \mathrm{~cm}$ (18 to 26 inches) is suggested, carried out perhaps every second year.

Allocate 1 to 6 minutes per tree per year, and ensure pruning personnel know to remove unwanted branches before trees waste reserves and growth on them and they become established. Although not all trees are readily amenable, it may be helpful to visualize a basic balanced branch structure (see Figure 5), which serves as a strong foundation for sustained high yields of high-quality fruit.

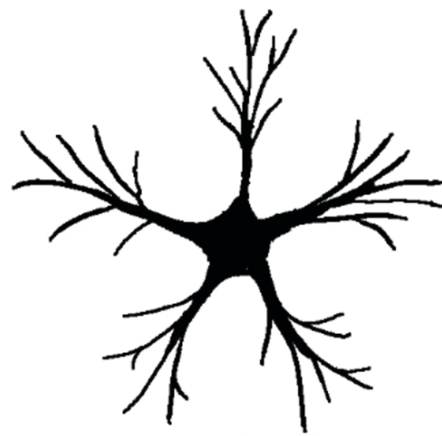

Like this

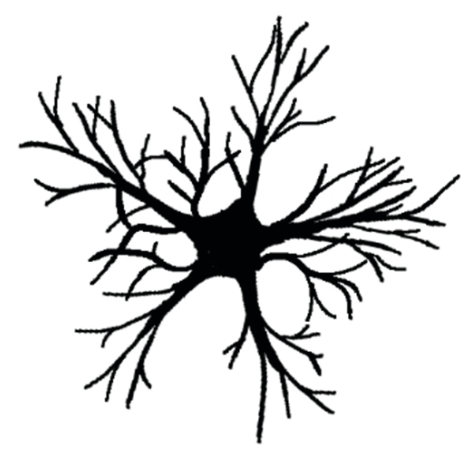

Not like this
Figure 4. A diagrammatic representation of correct scaffold branch orientation: outward, like the spokes of a wheel, with no crowding from 5 main branches (diagram on left) rather than forming a full and bushy center (diagram on right).

Credits: Timothy Ebert, UF/IFAS CREC

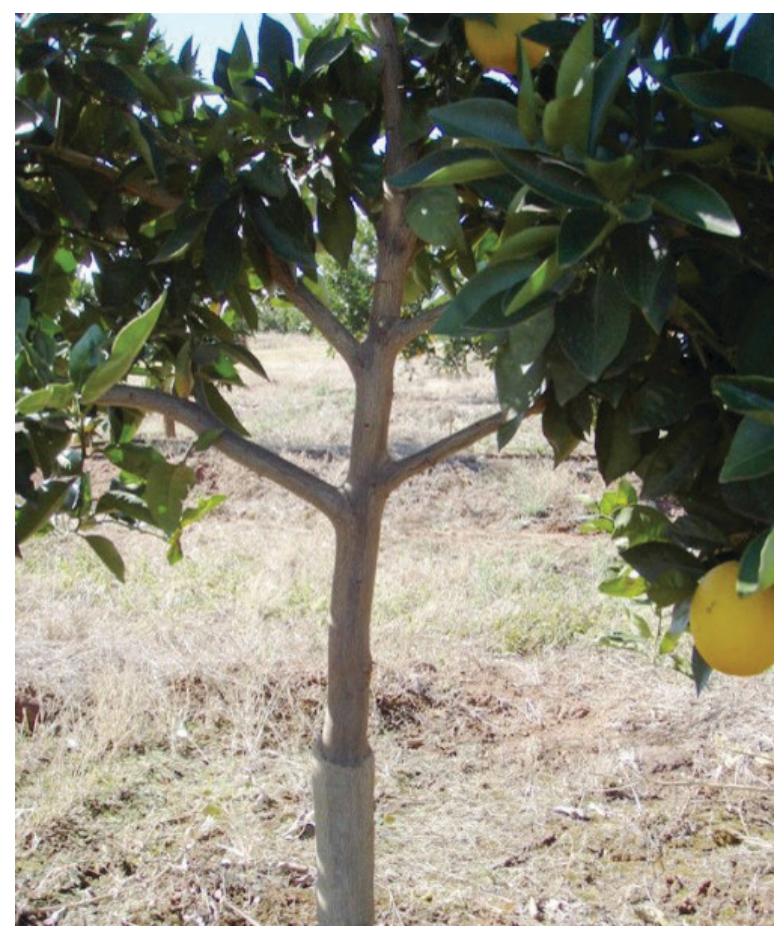

Figure 5. Aim to maintain tree structural "balance," comprising those well-spaced, mechanically strong, correctly oriented scaffold branches that were chosen when nonbearing trees were trained. This permanent structure, or something similar, is the foundation for a productive lifespan of the grove.

Credits: International Citrus Technologies Pty Ltd, Western Australia

\section{Bearing Trees}

Even where trees have been trained early in their lives into good physical structure, canopy management remains an important part of citrus production, given the adverse effects of canopy spread, congestion, and the shade trees cast on themselves and their neighbors. The aim of canopy management in bearing trees is to maintain strong, balanced tree structure capable of bearing heavy crops of large fruit of uniformly high quality. In such trees, strong bearing wood is uniformly well-lit and supplied with a strong 
vascular system from a relatively simple system of supporting branches.

Of all cultural practices, pruning and management of the resulting vegetative regrowth is most likely to optimize both light distribution within canopies and sap flow to fruits. It also generates and maintains compact, well-lit, productive, and easy-to-manage trees that fit well into high-density production systems. The aspects to consider before proceeding with canopy management of bearing trees are time of pruning, tree containment, reduction of canopy density, and management of vegetative regrowth.

1. Time of pruning: Prune trees as soon after harvest as possible; once the risk of late freezes is low; and when pests and diseases are least active. Pruning trees at or just after budbreak (i.e., $\mathrm{BBCH}$ citrus phenological stages 01 to 09 , or see Figure 6) capitalizes on floral-inductive field conditions and encourages flowering and fruit set on high-quality bearing wood (strong bearing branch units, or SBBU, discussed later). Pruning later means that the tree has wasted resources on flowers that will be pruned off. Citrus trees have been successfully pruned during full bloom (and even later) by removing only poor-quality bearing wood (weak bearing branch units, or WBBU, especially in mandarins and oranges) and a few shading branches per tree. This "delayed" pruning, when conducted during a high-flowering or "on" year of trees in an alternate bearing cycle, is a form of crop manipulation through flower thinning. As a rule, pruning during bloom should be carried out with caution and focus on thin branches that have many flowers and few if any leaves. While this may result in a large number of flowers on the ground, remember that only $0.1 \%$ to $3 \%$ of flowers will end in a marketable fruit. The tree naturally aborts the remaining $97 \%$ to $99.9 \%$ (https://irrec.ifas.ufl.edu/ flcitrus/pdfs/short_course_and_workshop/citrus_flowering_97/Guardiola-Overview_of_Flower_Bud_Induction. pdf).

2. Tree containment: Keep canopies within their allocated space by reducing tree height and spread and by skirting. Height reduction is particularly important in CUPS, where tree canopies should never contact the screen house roof. This is to protect the roof, and because pest management on branches close to the roof becomes more difficult. These practices are usually done annually, as soon after harvest as possible, and make it easier for pruners to access tree canopies and concentrate on optimizing tree canopy form and function by using selective pruning.

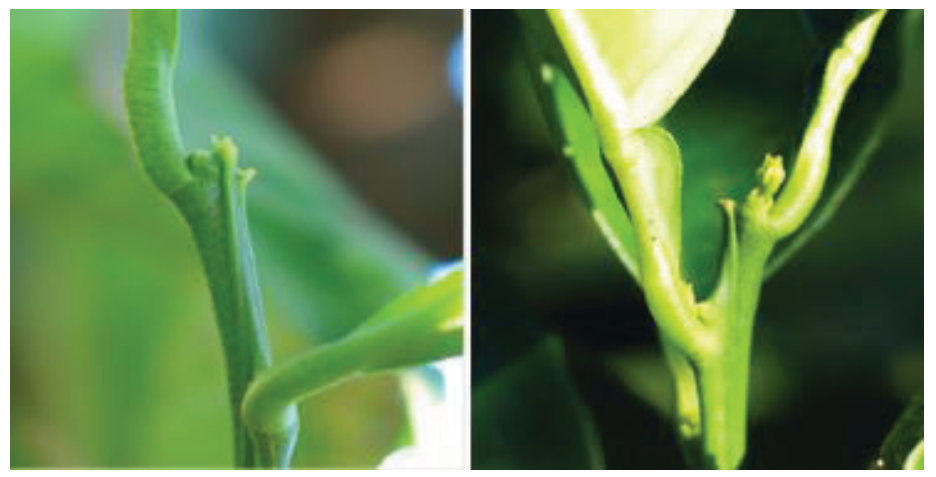

Figure 6. Ideal stage for pruning of bearing citrus trees: at or just after budbreak. This is not always possible in late-harvested varieties and where late freezes may be expected. The rule is: Prune as soon after harvest as possible.

Credits: International Citrus Technologies Pty Ltd, Western Australia

When reducing tree height, decide the maximum height to which trees will be allowed to grow.

In Florida it is generally accepted that tree height should not exceed two times the row-middle width. Thus, for a high-density planting with interrow spacing of $3.05 \mathrm{~m}$ (10 feet) and a $1.3 \mathrm{~m}$ (4 feet) row-middle space between canopies, trees should ideally never be taller than $2.6 \mathrm{~m} \mathrm{(8}$ feet).

Address excessive tree height with hand pruning by using thinning cuts, which remove at points of origin the 2 to 3 tallest, most upright, unbranched "leaders" present on the tree in that year. Other main tall branches in the center of the tree can be headed back to a lower, convenient side branch. Practical indications are that heavy mechanical topping of trees stimulates strong regrowth from the vicinity of the cuts, which shades lower fruiting wood and fails to solve the problem of tall branches reaching the screen house roof.

To address tree spread, prune long branches intruding into the grove interrows back far enough to maintain a practical interrow width for access of equipment. This also allows canopies of trees next to one another in the rows to loosely overlap each other. This degree of overlap helps maintain good light distribution (and effective spray penetration) through all canopies in the tree rows.

When skirting trees, remove entirely or shorten long, drooping branches to avoid physical contact with the soil, rain-driven soil splash, or under-canopy cultural practices (e.g., herbicide application, servicing of fertigation emitters) (Figure 7). In young trees, a convenient place to make a shortening cut is immediately below the intercalation, or "ring" - the junction between successive growth flushes (Figure 8). Alternately, the branch can be shortened back to 
a convenient side-branch to redirect the growth. A skirting height of 45 to $65 \mathrm{~cm}$ (18 to 26 inches) is suggested, carried out to keep branches and fruit clear of the soil, perhaps every second year.

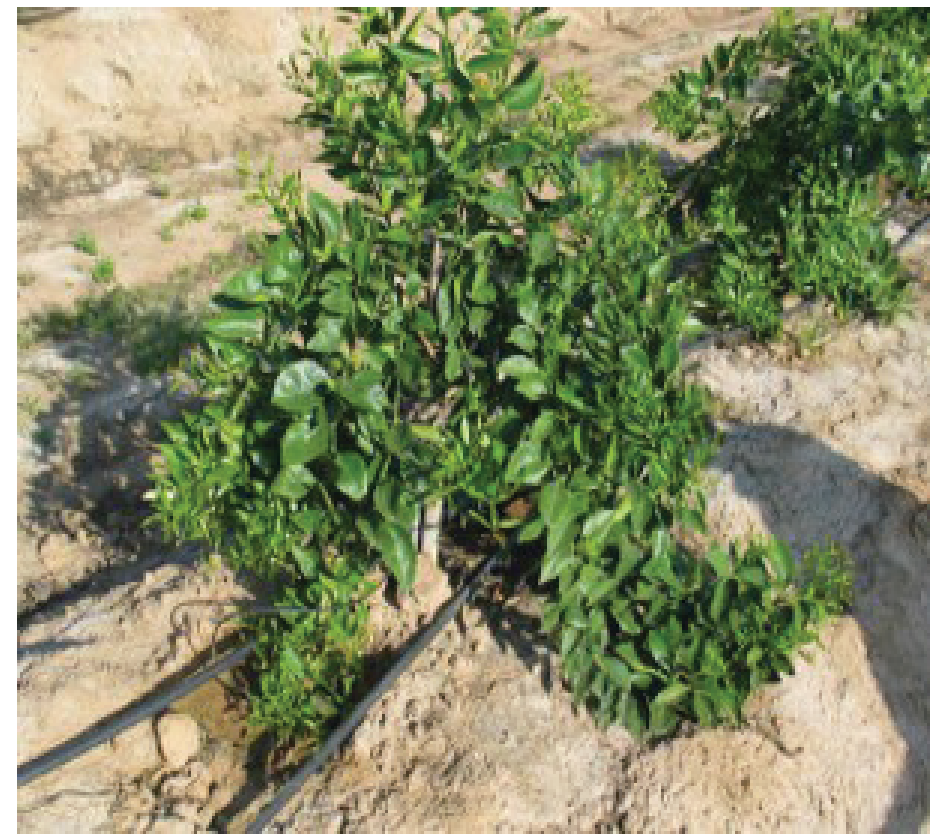

Figure 7. Trees should be skirted at a suitable height above ground level (for example, $45 \mathrm{~cm}$ above soil level) to keep foliage and fruit off the ground and above the level of soil "splash," and to facilitate under-tree operations such as fertigation, grove sanitation, and weed management.

Credits: International Citrus Technologies Pty Ltd, Western Australia

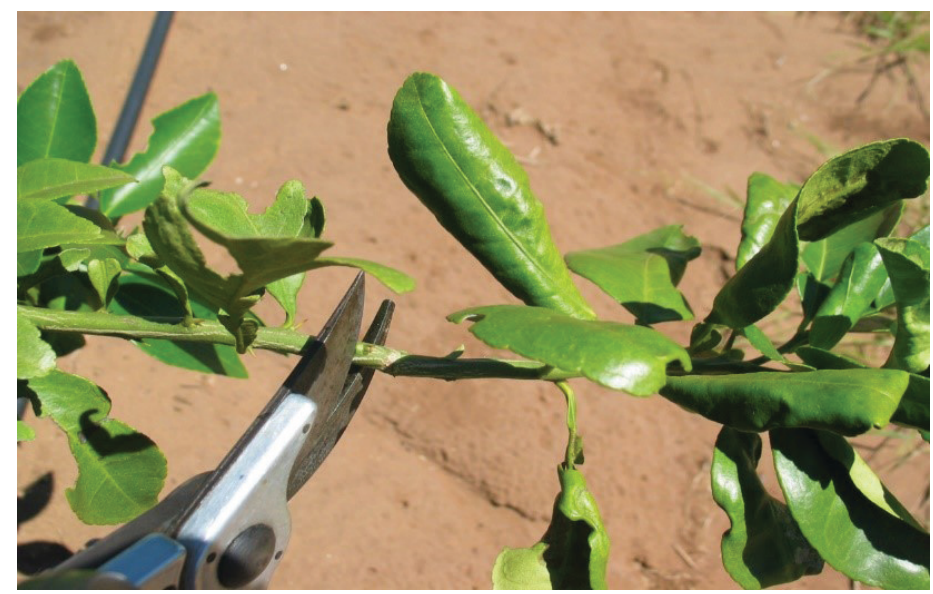

Figure 8. Shortening a long horizontal branch by cutting below the junction or intercalation between successive growth flushes, here located a centimeter or so to the right of the blades. This results in spaced lateral regrowth shoots on a shorter branch that does not touch the ground.

Credits: International Citrus Technologies Pty Ltd, Western Australia

Grove interrows may be maintained and trees skirted using mechanical hedging implements, although these generally cannot be sterilized practically.
3. Reduction of canopy density: After skirting and reduction of tree height and spread, open or thin out the canopy, but not excessively, to optimize light distribution and pesticide spray penetration. This may increase the allocation of tree reserves and energy to strong bearing branch units (SBBU), which in many mandarin and orange varieties are inherently more productive. This may be done annually in CUPS due to more vigorous tree growth, as follows:

- As with young trees, dead, diseased, or broken branches should be removed first, regardless of size or balance of the tree. Limit spread of pathogens by correctly disposing of diseased branches.

- Thin out the tops of trees by removing branches that grow back and cross over the center of the tree as well as branches that rub against each other, often causing bark damage and scarring (see Figures 9 and 10; upright, unbranched watershoots arising from tree centers).

Thin out to one branch any main branches that lie side by side or one above the other. These closely separated branches occupy the same space and compete with each other. Prevent this by cutting out either the left or right fork when side by side, favoring the better of the two and removing the weaker one, or the lower fork when branches fork "over/under."

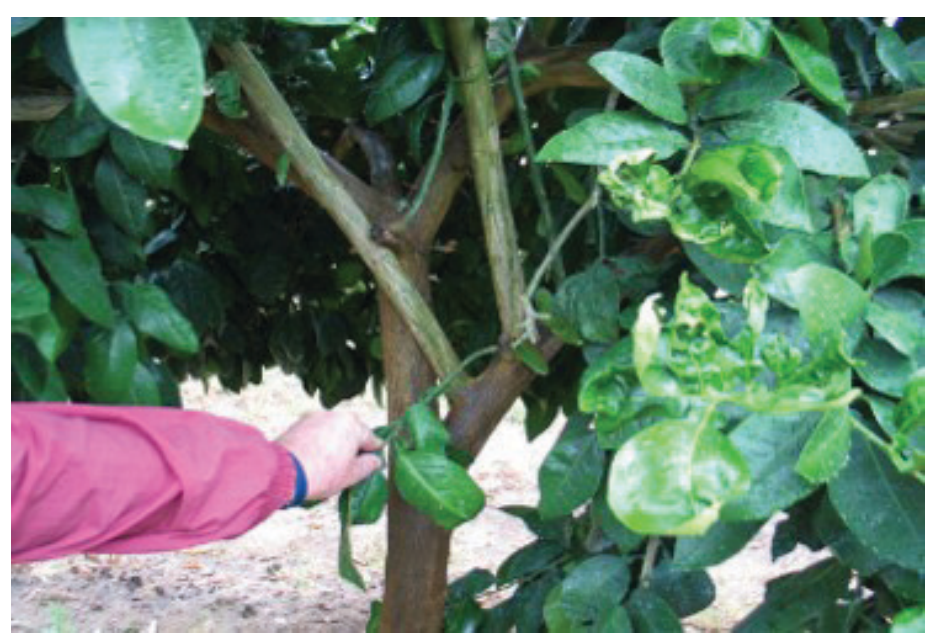

Figure 9. Two poorly positioned branches with green bark being pointed out. The one on the left is growing back toward the center of the tree and rubbing against other, better-positioned scaffold branches in the canopy above. The right-hand branch is growing up the center of the canopy and is shading and dominating the canopy beneath. It is the tallest branch on the tree shown. Both of these branches are also excessively vigorous. Both should be removed by cutting at their bases to intersect the so-called "branch collar." This speeds wound healing.

Credits: International Citrus Technologies Pty Ltd, Western Australia 


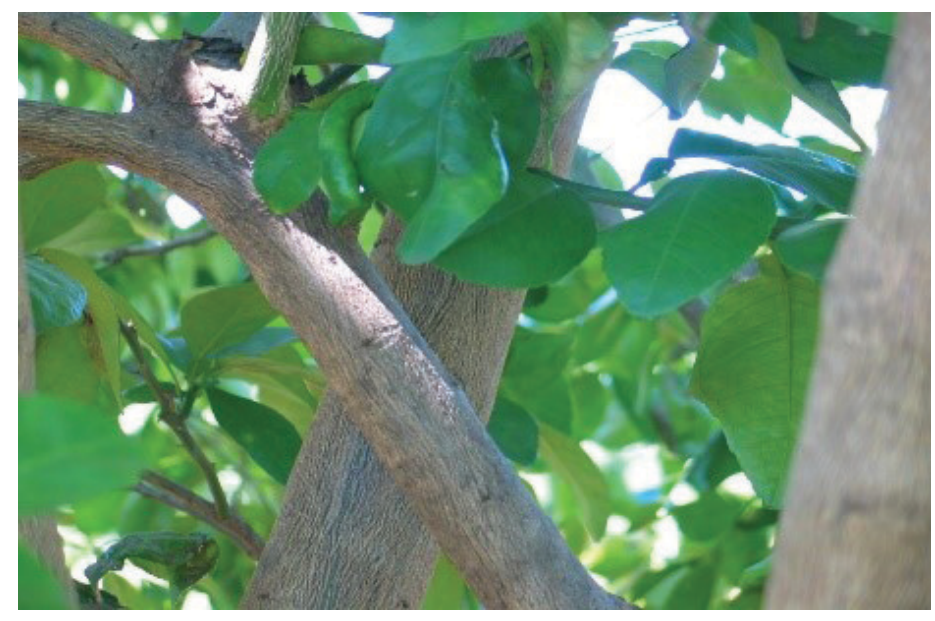

Figure 10. A poorly positioned branch "crossing over" or growing back into the canopy and over the center of the tree instead of radiating outwards. Such branches must be removed by cutting at the branch collar at their base.

Credits: International Citrus Technologies Pty Ltd, Western Australia

- Finally, it may pay to remove poor-quality bearing wood throughout the canopy. Cut off weak bearing branch units (WBBU), which are recognizable as pendulous "hangers" arising from underneath their supporting scaffolds. They are weak, long, thin, spindly, highly branched structures bearing few, small, old, or yellow leaves, and they give rise to mostly leafless inflorescences in shaded canopy zones (Figure 11).

As for nonbearing trees, main branches should occupy their own sector of the canopy, radiating outward with approximately equal vigor, like the spokes of a wagon wheel. Branches that conform poorly should be cut out before trees waste reserves and growth on them and they become established. Skilled pruners work to retain and optimize this basic balanced structure. This pruning also clears the way for flowering and fruiting on SBBU, which comprise relatively young, upright branches arising from the top surface of their supporting scaffolds, which are relatively short, thick, and sparingly branched. These SBBU bear many dark-green, physiologically active leaves and produce mostly leafy inflorescences and heavier, larger fruit (Figure 11). Pruners must recognize these branches and leave them in place because they are high-quality bearing wood for sustained, heavy production of high-quality fruit.

Regarding the intensity of pruning, cut only as much canopy from bearing trees as will achieve well-balanced structure, and never more than $15 \%$ to $20 \%$ of the canopy in any given operation, except where trees have been affected by branch breakage or freeze damage. Skillful pruners at once recognize in each tree the two or three most important cuts to make, and they use most of their allocated time to address these problem branches before moving on. Repeated, annual canopy management operations transform and maintain favorable tree structure and productivity and lay the foundation for sustained heavy crops of high-quality fruit. Practical experiences suggest pruners should spend no more than 5 to 6 minutes per tree, per year, and that repeated light and selective pruning significantly improves tree productivity.
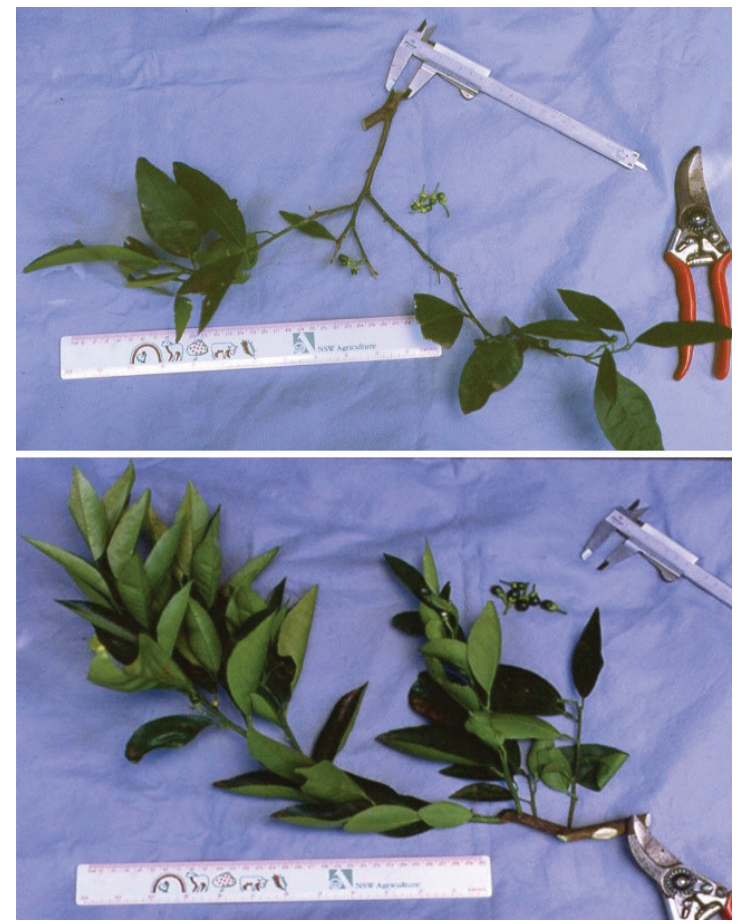

Figure 11. Top: Weak bearing branch units (WBBU) arising from the underside of a branch from a 'Bellamy' navel orange tree. These should be removed by cuts made to the undersides of their supporting branches. The supporting branch is indicated by the jaws of the Vernier caliper. Bottom: An example of strong bearing branch units (SBBU) arising from the top of the supporting branch in 'Bellamy' navel orange. Note the relatively large fruitlet diameter compared with those from WBBU in Figure 11, top. The supporting branch, trimmed for clarity, is indicated by the pruning shear blades.

Credits: International Citrus Technologies Pty Ltd, Western Australia

4. Management of vegetative regrowth: Healthy trees respond by producing localized regrowth close to where cuts were made and general regrowth throughout well-lit parts of the canopy. Both should be managed some 4 to 5 months after pruning (i.e., in late summer/early fall) to maintain good canopy illumination and effective spray coverage, optimize bearing potential of regrowth, and improve fruit quality. Regrowth should be spaced out by hand-thinning to leave new shoots 10 to $15 \mathrm{~cm} \mathrm{(4}$ to 6 inches) apart. Well-placed but excessively vigorous watershoots may be bent and secured toward the horizontal to greatly slow their extension growth, stimulate lateral shoot growth, and make the new branch fruitful (Figure 12). Once "set" in its new orientation, a bent shoot can later be shortened to a convenient side-branch, 
leaving in place a new, strong scaffold branch that bears large fruit (Figure 13).

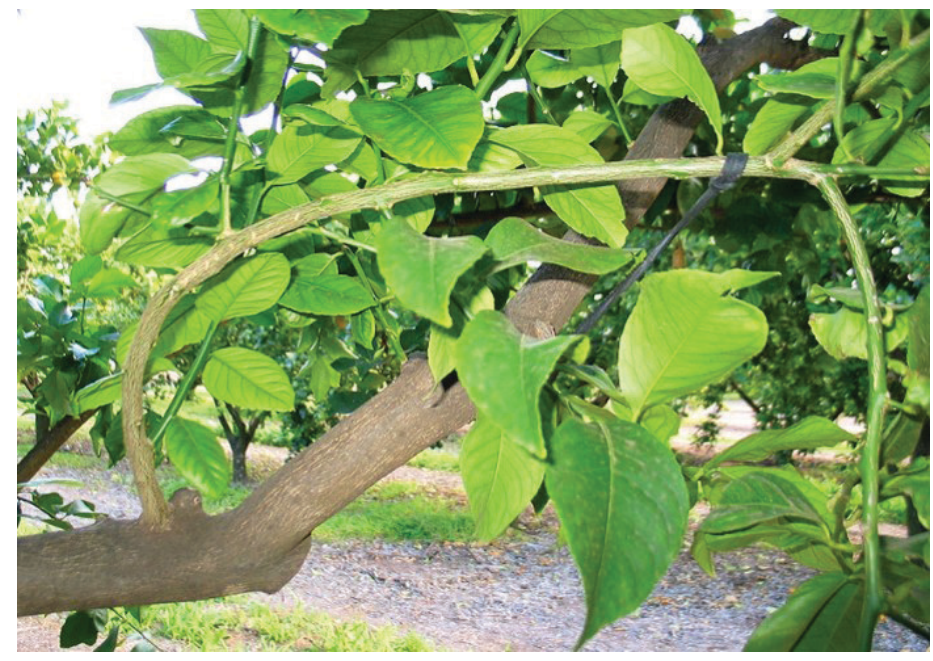

Figure 12. Bending a vigorous watershoot to induce lateral branching. A previously upright, vigorous lemon branch has been drawn down with a degradable natural rubber tree-training band, which within months weathers and breaks down in place, does not damage the branch it encircles, and leaves the branch permanently bent over. Credits: International Citrus Technologies Pty Ltd, Western Australia

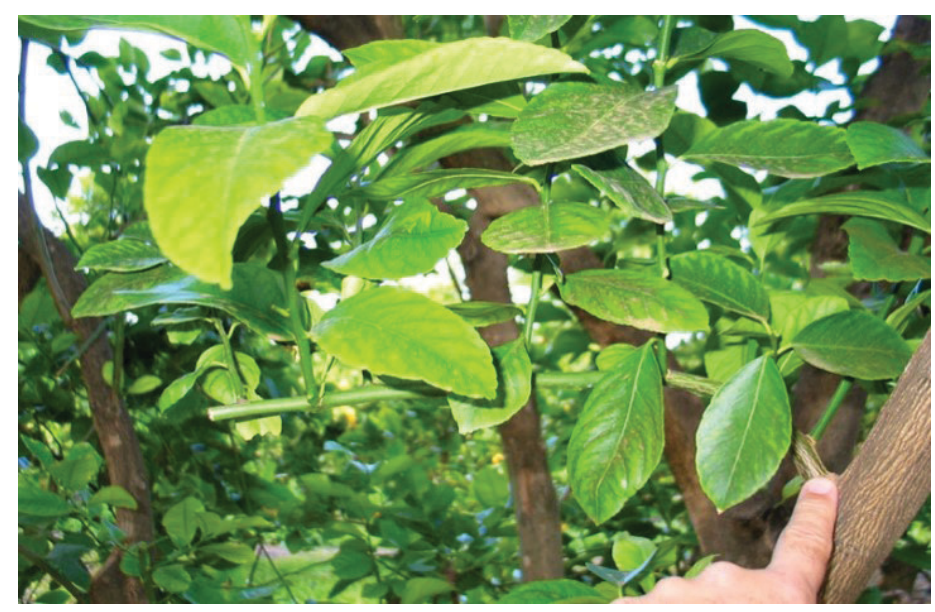

Figure 13. The bent watershoot may later be shortened with secateurs (usually in early fall) to leave behind a strong, short branch, bearing well-spaced lateral shoots that mature to form SBBU, which usually produce large, high-quality, easily harvested fruit.

Credits: International Citrus Technologies Pty Ltd, Western Australia

General considerations: Canopy management is one of a number of cultural practices forming the basis of best management practices in groves; fertigation, pest and disease management, fruit size management or thinning, grove sanitation, and harvest are others. Citrus growers are best able to assess the performance of their trees and to plan and implement their canopy management activities accordingly. Consider the following:

- The main aim of pruning is to guide young trees toward the correct form for precocious fruiting and to maintain productivity and amenability by cutting light and spray channels into the resulting compact, leafy, fruitful, mechanically strong and geometrically balanced tree canopies.

- To reduce risk of disease transmission (e.g., citrus exocortis viroid, Asian citrus canker, HLB), always use properly sterilized tools, sprayed or dipped between each tree with one of the following sterilants: Clorox solution (25\%, or one part product plus three parts clean water. Note: this is highly corrosive, so rinse and oil blades after use); Pine oil (e.g., Pine-Sol: 25\% solution in water); Isopropyl alcohol (70\%, or denatured ethanol $95 \%$, both diluted one part alcohol plus one part water); or QAC (quaternary ammonium compound) as directed on the product label. Keep these substances clear of pruning wounds; they inhibit callus formation and delay healing.

- Growers are strongly advised to keep detailed records of their own trees' phenological cycles and of canopy management operations addressing the important questions: What was done, where, when, how, and what follow-up was conducted? What were the trees' responses?

- Each pruner should efficiently use allocated time to improve structure and function of each tree. To do this, a consistent procedure should be followed. Pruning teams need clear instructions on exactly what to do and the time allocated to do it, and their work should be checked continually (i.e., several times daily at least) by knowledgeable supervisors and crew chiefs. Pruners need clear instructions: for example, "spend three minutes per tree making three to six cuts to remove cross-over branches; also thin out forked branches to singles, shorten to convenient side-branches any main branches growing downwards, and then move on to the next tree." Remember: this is an ongoing process, with trees pruned lightly and selectively every year. Accept that some trees possess poor structure that cannot be corrected given the limitations of time and cost. Provided most trees have a reasonable basic shape, "ideal" canopy form is not essential for sustained, high production.

- Prune only as little as necessary, and never remove more than $15 \%$ to $20 \%$ of a tree's canopy in a single year, except when removing broken branches. Ensure the bulk of material removed comprises unwanted wood, that is, only dead, diseased, and dysfunctional branches in the following hierarchy: dead $>$ broken $>$ oldest $>$ weak BBU $>$ BBU with a large number of flowers in leafless inflorescences ("bouquet bloom," "white blossom").

- Use thinning cuts, removing entire unwanted scaffolds, branches, or shoots. In bearing trees, make most of the pruning cuts to the underside of scaffolds or branches 
to cut off so-called "hangers," which are examples of "exhausted" shoots or WBBU. This "layering" effectively opens and maintains desirable light and spray channels into tree canopies. Make cuts through the basal branch collar for fastest healing.

- Looking down into a pruned tree, one should see as few pruning cuts as possible, because cuts on the upper surfaces of branches give rise to strong, upright, unfruitful shoots (called "risers") that intercept sap flow in branches and cast shade on better-quality fruiting wood below.

\section{References and Articles for More Information}

Agusti, M., S. Zaragoza, H. Bleiholder, L. Buhr, H. Hack, R. Klose, and R. Stauss. 1995. "Escala BBCH para la descripción de los estadios fenológicos del desarrollo de los agrios (Gén. Citrus)." Levante Agricola 3:189-199. https:// ojs.openagrar.de/index.php/BBCH/article/view/479/429

Agusti, M., S. Zaragosa, H. Bleiholder, L. Buhr, H. Hack, R. Klose, and R. Staub. 2000. "The BBCH Scale for Describing Phenological Stages in Citrus Development." Proceedings of the International Society of Citriculture 1:445-446.

Bevington, K., S. Falivene, and A. Krajewski. 2003. Pruning for Fruit Size. Sydney: NSW Agriculture/Horticulture Australia.

"Disinfecting Your Garden Tools." 2015. UF/IFAS Gardening Solutions. Accessed 31 January 2018. https:// gardeningsolutions.ifas.ufl.edu/care/tools-and-equipment/ disinfecting-tools.html

Fake, C. 2012. Pruning Citrus. Publication No. 31-008C. Placer and Nevada Counties: University of California Cooperative Extension.

Gucci, R., and C. Cantini. 2000. Pruning and Training Systems for Modern Olive Growing. Collingwood, VIC, Australia: CSIRO Publishing.

Khurshid, T., and A. Krajewski. 2010. "Bearing Branch Units Developed on Branches Hedged during Flowering Produce Large 'Washington' Navel (Citrus sinensis L. Osbeck) Oranges." International Journal of Fruit Science 10 (3): 215-227. https://doi.org/10.1080/15538362.2010.5104 17

Krajewski, A. 1996. "Pruning of Citrus in Southern Africa: A Hacker's Guide.” Citrus Journal 6 (4): 19-23.
Krajewski, A., and S. Krajewski. 2011. "Canopy Management of Sweet Orange, Grapefruit, Lemon, Lime and Mandarin Trees in the Tropics: Principles, Practices and Commercial Experiences." Acta Horticulturae 894:65-76.

Krajewski, A., and T. Pittaway. 2000. "Manipulation of Citrus Flowering and Fruiting by Pruning." Proceedings of the International Society of Citriculture 1:357-360.

Schumann, A. W., A. Singerman, A. L. Wright, and R. S. Ferrarezi. 2017. Citrus Under Protective Screen (CUPS) Production Systems. CMG19. Gainesville: University of Florida Institute of Food and Agricultural Sciences. https:// edis.ifas.ufl.edu/hs1304

Tufts, W., and R. Harris. 1955. Pruning Deciduous Trees. Circular 444. California Agricultural Experiment Station Extension Service, University of California.

Van den Ende, B. 2009. "How to Keep Your Trees Calm: Heading for Trouble." Good Fruit Grower. Accessed 14 June 2019. http://www.goodfruit.com/heading-for-trouble/

\section{Acknowledgments}

This material is based upon work supported by the National Institute of Food and Agriculture, U.S. Department of Agriculture, under award number 2018-70016-27387. 